\title{
Neural Coding by Two Classes of Principal Cells in the Mouse Piriform Cortex
}

\author{
Norimitsu Suzuki and John M. Bekkers \\ Division of Neuroscience, John Curtin School of Medical Research, The Australian National University, Canberra, Australian Capital Territory 0200, \\ Australia
}

The piriform (or primary olfactory) cortex is a trilaminar structure that is the first cortical destination of olfactory information, receiving monosynaptic input from the olfactory bulb. Here, we show that the main input layer of the piriform cortex, layer II, is dominated by two classes of principal neurons, superficial pyramidal (SP) and semilunar (SL) cells, with strikingly different properties. Action potentials in SP cells are followed by a $\mathrm{Ni}^{2+}$-sensitive afterdepolarization that promotes burst firing, whereas SL cells fire nonbursting action potentials that are followed by a powerful afterhyperpolarization. Synaptic inputs from the olfactory bulb onto SP cells exhibit prominent paired-pulse facilitation, which is attributable to residual presynaptic $\mathrm{Ca}^{2+}$ and a low probability of neurotransmitter release. In contrast, the same inputs onto SL cells do not facilitate. These distinctive synaptic and firing properties cause SP and SL cells to respond differently to in vivo-like bursts of afferent stimulation: SP cells tend to fire bursts of output action potentials at a higher frequency than the input, whereas SL cells tend to fire at a lower frequency than the input. When connected together in the canonical circuit of the piriform cortex, SP and SL cells transform the pattern of synaptic inputs they receive from the olfactory bulb, dispersing the firing rate and latency of output action potentials to an extent that depends on the strength of the input. Thus, the presence of two types of principal cells in layer II of the piriform cortex may underlie coding strategies used for the representation of odors.

Key words: action potential; calcium; EPSP; olfaction; pyramidal cell; synaptic integration

\section{Introduction}

The piriform cortex is a phylogenetically ancient cortical region that anatomically resembles the hippocampus (Neville and Haberly, 2004). Like the hippocampus, the piriform cortex is a strongly laminated structure with only three layers (cf. six layers in the neocortex). Layer II of the piriform cortex contains densely packed principal neurons that receive the majority of inputs from the previous stage of the olfactory system, the main olfactory bulb, which in turn receives inputs from odorant receptors in the olfactory epithelium. Thus, the layer II principal neurons in the piriform cortex receive inputs that do not pass through the thalamus, and are only two synapses removed from the primary stimulus (Wilson, 2001). The comparatively simple architecture of the piriform cortex, together with its well defined function (to process odorant information from the olfactory bulb) (Wilson, 2003), suggests that it may be a useful system in which to study sensory processing.

An obvious starting point for study of the piriform cortex is the neurons populating the main input layer, layer II. Principal neurons in layer II comprise two morphologically distinctive cell

Received Aug. 11, 2006; revised 0ct. 5, 2006; accepted 0ct. 10, 2006.

This work was supported by Project Grant 224240 from the National Health and Medical Research Council of Australia and by recurrent funding from the John Curtin School of Medical Research. We thank Sharon Oleskevich for advice on the use of EGTA-AM and Garry Rodda for excellent technical assistance.

Correspondence should be addressed to Dr. John M. Bekkers, Division of Neuroscience, John Curtin School of Medical Research, Building 54, The Australian National University, Canberra, ACT 0200, Australia. E-mail: John.Bekkers@anu.edu.au.

DOI:10.1523/JNEUROSCI.3473-06.2006

Copyright $\odot 2006$ Society for Neuroscience $\quad 0270-6474 / 06 / 2611938-10 \$ 15.00 / 0$ types: superficial pyramidal (SP) cells, which resemble hippocampal pyramidal neurons, and semilunar (SL) cells, which resemble dentate granule cells in that they typically lack basal dendrites (see Fig. 1A) (Haberly, 1983; Neville and Haberly, 2004). Surprisingly, despite their abundance (Haberly and Price, 1978) and likely importance for olfactory processing, SL cells have not specifically been studied by neurophysiologists. Some of the electrical properties of SP cells have been described previously (Haberly and Bower, 1984; Hasselmo and Bower, 1992; Gellman and Aghajanian, 1993; Barkai and Hasselmo, 1994; Kapur et al., 1997; Protopapas and Bower, 2001; Franks and Isaacson, 2005, 2006), but in many of these cases it is even unclear whether the dataset comprised a mixture of SP and SL cells. Here, we show that it is essential to maintain a distinction between SP and SL cells because they exhibit dramatically different firing and synaptic properties, with likely ramifications for neural coding.

The canonical circuit in the piriform cortex is thought to comprise two layers of synaptic processing: afferent inputs from the olfactory bulb are received on the distal dendrites of layer II and III principal cells, and the outputs of these cells in turn form diffuse associational and commissural synapses on the proximal dendrites of other principal cells (Johnson et al., 2000). We applied naturalistic electrical stimulation, based on in vivo recordings, to SP and SL cells in brain slices and traced the responses through the two synaptic layers of the canonical circuit. We found that SP and SL cells applied characteristic transformations to their inputs and, in combination, had the effect of dispersing the properties of the output action potentials (APs) to an extent 
that depended on the strength of olfactory input. Thus, sensory processing in the piriform cortex may employ a coding strategy that depends critically on the presence of two distinctive cell types in its main input layer.

\section{Materials and Methods}

Slice preparation. Mice (C57BL/6J; 13-30 d of age; either sex) were anesthetized with isoflurane and rapidly decapitated, in accordance with the Animal Experimentation Ethics Committee of The Australian National University. Similar results were obtained for all ages of animals, so the data were combined. Coronal or parasagittal slices (300 $\mu \mathrm{m}$ thick) were prepared from the anterior piriform cortex using standard techniques (Bekkers and Delaney, 2001). Briefly, slices were cut in ice-cold slicing solution comprising the following (in $\mathrm{mM}$ ): $125 \mathrm{NaCl}, 3 \mathrm{KCl}, 0.5 \mathrm{CaCl}_{2}, 6$ $\mathrm{MgCl}_{2}, 25 \mathrm{NaHCO}_{3}, 1.25 \mathrm{NaH}_{2} \mathrm{PO}_{4}, 10$ glucose, 0.5 ascorbic acid, and then transferred to a holding chamber containing artificial CSF (ACSF) at $35^{\circ} \mathrm{C}$ plus $2 \mathrm{~mm}$ ascorbic acid and $3 \mathrm{~mm}$ pyruvate. ACSF contained the following (in mM): $125 \mathrm{NaCl}, 3 \mathrm{KCl}, 2 \mathrm{CaCl}_{2}, 1 \mathrm{MgCl}_{2}, 25 \mathrm{NaHCO}_{3}, 1.25$ $\mathrm{NaH}_{2} \mathrm{PO}_{4}$, and 25 glucose. After $1 \mathrm{~h}$ of incubation, the slices were allowed to cool to room temperature. All solutions were continuously bubbled with $5 \% \mathrm{CO}_{2} / 95 \% \mathrm{O}_{2}$ (carbogen).

Electrophysiology. Slices in the recording chamber were maintained at $34-35^{\circ} \mathrm{C}$ in a continuous flow of carbogen-bubbled ACSF. Patch electrodes were pulled from borosilicate glass and had resistances of 3-4 M $\Omega$ (for voltage clamp) or 6-10 $\mathrm{M} \Omega$ (for current clamp) when filled with internal solution comprising the following (in mM): $135 \mathrm{~K}$-methylsulfate, $7 \mathrm{KCl}, 0.1$ EGTA, $2 \mathrm{Na}_{2} \mathrm{ATP}, 2 \mathrm{MgCl}, 0.3 \mathrm{Na}_{2} \mathrm{GTP}, 10$ HEPES at pH 7.2, supplemented with $0.2 \%$ biocytin and $50 \mu \mathrm{M}$ Alexa- 488 (Invitrogen, Mt. Waverley, Australia). A MultiClamp 700A amplifier (Molecular Devices, Union City, CA) was used to obtain whole-cell recordings from the somata of visually identified SP or SL cells, distinguished according to their morphology and somatic location (SP, deep layer II; SL, superficial layer II) (Neville and Haberly, 2004). In current-clamp recordings, capacitance neutralization and bridge balance were carefully adjusted and checked frequently during the experiment. In voltage-clamp recordings, the soma was clamped at $-70 \mathrm{mV}$ and the pipette solution contained $135 \mathrm{~mm}$ Cs methane sulfonate instead of K-methylsulfate. In some experiments, the bath solution contained a low concentration of CNQX (6-cyano-7-nitroquinoxaline-2,3-dione) $(1 \mu \mathrm{M})$ or DNQX (6,7-dinitroquinoxaline-2,3-dione) $(1 \mu \mathrm{M})$, plus DL-APV (DL-2-amino-5-phosphonovaleric acid) $(50 \mu \mathrm{M})$, to reduce the amplitudes of EPSCs and minimize polysynaptic activity. Bicuculline $(10 \mu \mathrm{M})$ or picrotoxin $(100 \mu \mathrm{M})$ was also added to the bath solution for voltage-clamp experiments to block $\mathrm{GABA}_{\mathrm{A}}$-mediated inhibition. When measuring NMDA EPSCs, the ACSF contained $10 \mu \mathrm{M}$ DNQX but not $\mathrm{MgCl}_{2}$. EGTA-AM (Invitrogen) was dissolved in dimethylsulfoxide at $100 \mathrm{~mm}$ before dilution in ACSF to 30 $\mu \mathrm{M}$. EGTA-AM-containing ACSF was perfused for $15 \mathrm{~min}$, and then washed out; recordings were made in normal ACSF starting 5 min after washout. The extracellular stimulator was a glass pipette (tip diameter, $\sim 10 \mu \mathrm{m}$ ) that was coated with silver paint and filled with $1 \mathrm{~m} \mathrm{NaCl}$. Brief $(200 \mu \mathrm{s})$ pulses were provided by a constant-current source. "Artificial" EPSPs were generated by injecting at the soma an exponentially decaying current (amplitude, 250-500 pA; instantaneous on-step; decay time constant, $10 \mathrm{~ms}$ ). Data were acquired using an ITC-18 interface (Instrutech, Great Neck, NY) controlled by Axograph 4.9 (Axograph Scientific, Sydney, Australia). Voltages have not been corrected for the liquid junction potential, measured to be $-7 \mathrm{mV}$.

Confocal microscopy. Calcium imaging was done with a Zeiss (Oberkochen, Germany) LSM 510 confocal microscope using a 40×/0.8 numerical aperture water immersion objective. Oregon Green 488 BAPTA-1 (OGB-1) (200 $\mu \mathrm{M}$; Invitrogen), or its lower-affinity analogs OGB-6F $(200 \mu \mathrm{M})$ or OGB-5N $(200 \mu \mathrm{M})$, were added to the Kmethylsulfate intracellular solution, excluding EGTA. Line scans were done at $5 \mathrm{~ms}$ intervals across the dendrite at the indicated locations (see Fig. $3 A$, red lines). Similar results were obtained for all indicators, indicating that dye saturation was not a concern under our conditions.

Analysis. Analysis was done using Axograph or Igor Pro (Wavemetrics, Lake Oswego, OR). Input resistance was calculated from the voltage responses to a series of hyperpolarizing current steps in current-clamp mode. Membrane time constant was measured by fitting a single exponential to the voltage response to an $80 \mathrm{pA}$ hyperpolarizing current step. The burst index was calculated as $\Delta t_{7} / \Delta t_{1}$, where $\Delta t_{1}$ is the time interval between the first and second APs, and $\Delta t_{7}$ is the interval between the seventh and eighth APs, in a 200-ms-long train of eight APs. Instantaneous AP frequency was defined as $1 / \Delta t_{n}$ for the $n$th interval. Amplitudes of evoked EPSCs were measured by averaging over a 0.5 - to 1-ms-long window around the peak. The amplitude of the second EPSC in pairedpulse experiments was measured after correcting for the overlapping tail of the first EPSC. Normalized stimulus strength (see Figs. 7-9) was calculated for each cell by normalizing the absolute stimulator setting (in microamperes) to the minimum setting that elicited, on average, a single AP per train of five stimuli when averaging across 10-20 such trains. The averaged plot of mean AP frequency versus normalized stimulus (see Fig. $7 F$ ) was calculated as follows. Data for individual SP or SL cells stimulated in layer Ib with $40 \mathrm{~Hz}(n=10$ cells), $20 \mathrm{~Hz}(n=4-5)$, or bursting $40 \mathrm{~Hz}(n=4-5)$ trains (see Results) were combined and ranked in order of increasing normalized stimulus strength. For successive groups of 15 data points, the average and SD of both the mean AP frequency and normalized stimulus strength were calculated. Figure $7 F$ plots this average $\pm 1 S D$ (shaded bands) versus the averaged normalized stimulus for each group of 15 . Line scans were analyzed by averaging fluorescence intensity across the width of the dendrite and calculating $\Delta F / F$ with respect to the baseline fluorescence before the stimulus. Numerical results in this paper are given as mean $\pm \mathrm{SE}$, with $n=$ number of cells. Groups were compared using the paired or unpaired two-sided Student's $t$ test, with significance as indicated.

\section{Results}

Two types of principal neuron in layer II of piriform cortex

SP cells (Fig. 1A, left) and SL cells (Fig. 1A, right) are morphologically distinctive but are embedded in similar circuits in the piriform cortex (ul Quraish et al., 2004; Yang et al., 2004). Both receive monosynaptic input from the olfactory bulb via the lateral olfactory tract (LOT), which forms excitatory synapses on the distal apical dendrites in layer Ia (see Fig. $7 E$ ). Both also receive associational (Assn) and commissural inputs from other SP and SL cells, which form excitatory synapses on proximal apical dendrites in layer Ib and (for SP cells) on basal dendrites in layer III. However, despite these superficial similarities, we report here that SP and SL cells differ dramatically in their functional properties, suggesting that together they enrich the complexity of olfactory coding.

We began by comparing the intrinsic electrical properties of the two types of cells. SP and SL cells were found to exhibit significantly different input resistances (SP: $118 \pm 8 \mathrm{M} \Omega, n=41$; SL: $240 \pm 10 \mathrm{M} \Omega, n=21, p<0.001)$, membrane time constants (SP: $11.2 \pm 2.3 \mathrm{~ms}, n=15$; SL: $22.0 \pm 1.4 \mathrm{~ms}, n=23, p<0.001$ ) and resting potentials (SP: $-74.7 \pm 0.6 \mathrm{mV}, n=41$; SL: $-68.8 \pm$ $0.9 \mathrm{mV}, n=21, p<0.001)$, all measured shortly after attaining the whole-cell configuration.

In response to a depolarizing current step, SP cells usually fired APs with an initial high-frequency burst (Fig. 1B, left), whereas SL cells fired a regular train of APs (Fig. $1 B$, right). Averaged data confirmed this finding (Fig. 1C): the instantaneous firing frequency for the first two APs in a train of eight APs was significantly larger in SP cells than in SL cells $(154.5 \pm 6.4 \mathrm{~Hz}, n=$ 41; cf. $55.4 \pm 2.2 \mathrm{~Hz}, n=21 ; p<0.001$ ). This bursting behavior was quantified by calculating the burst index, which is unity for a regular-spiking cell and increases with stronger bursting (see Materials and Methods). A histogram of the burst index shows that it is close to 1 for SL cells (mean, $1.40 \pm 0.06 ; n=21$ ) (Fig. $1 D$ ), indicative of regular spiking. In contrast, the burst index for SP cells, although variable, is always $>2($ mean, $5.84 \pm 0.29 ; n=41)$ 

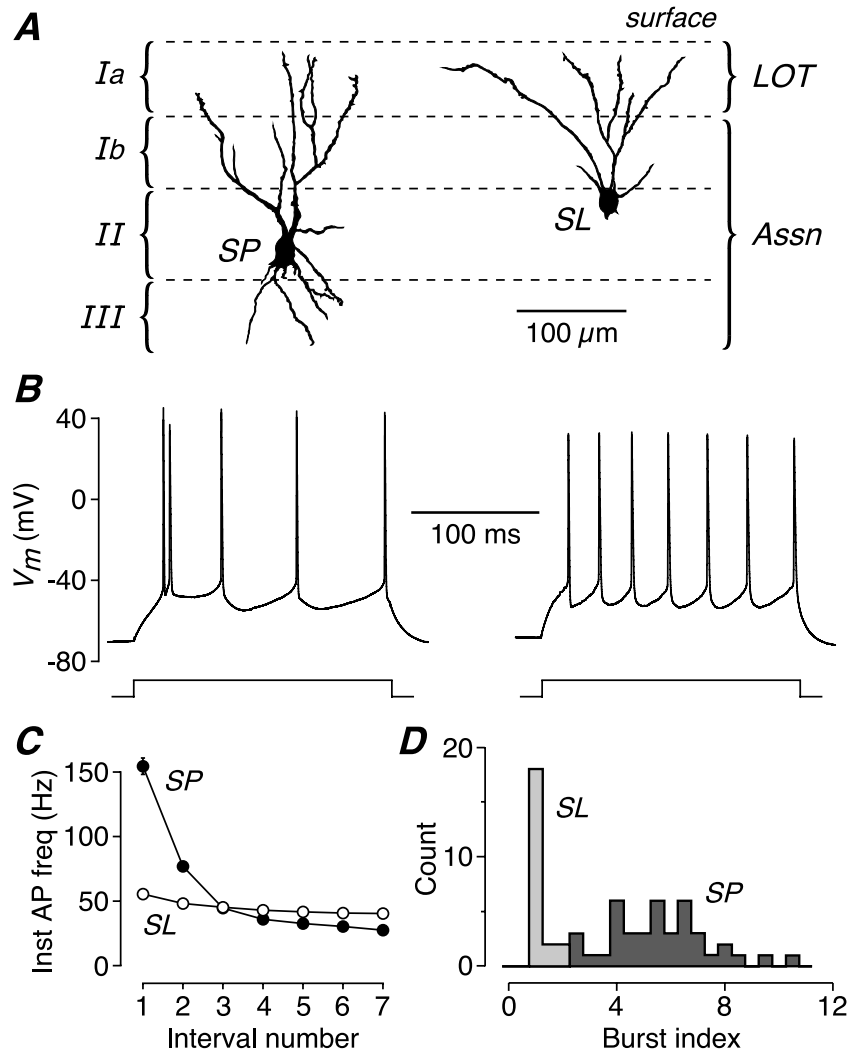

Figure 1. The two main types of principal neuron in layer Il of piriform cortex have distinctive firing properties. $A$, Dendritic morphology of an SP cell and an SL cell in the piriform cortex of a 16-d-old mouse. The approximate locations of the cortical layers are shown. Both SP and SL cells receive afferent inputs from the olfactory bulb via the LOT, which forms synapses on the distal apical dendrites in layer la. Both cell types also receive associational/commissural inputs (Assn) from other SP and SL cells via synapses on their proximal apical dendrites in layer Ib and (for SP cells) on basal dendrites in layer III. $\boldsymbol{B}$, Typical AP firing pattern in an SP (left) and an SL cell (right) in response to a 200-ms-long, $200 \mathrm{pA}$ current step. SP cells tend to fire a burst of APs at step onset. C, Mean instantaneous AP firing rate for SP $(n=41)$ and SL $(n=21)$ cells, plotted against the number of the interval between consecutive APs, calculated for the current step that produced eight APs. SP cells fire an initial burst of two to three APs at up to $150 \mathrm{~Hz}$, whereas SL cells fire APs regularly at $\sim 50 \mathrm{~Hz}$. $D$, Histogram of the burst index for SP $(n=41)$ and $S L(n=$ 21) cells. The burst index for SL cells clusters around 1, indicating regular spiking, whereas the index for SP cells is always $>2$.

(Fig. 1D). Hence, SP cells consistently exhibit burst firing at the onset of a current step. Later, we show that AP burst firing is also provoked by synaptic stimulation of SP cells, but rarely SL cells.

\section{Burst firing requires nickel-sensitive $\mathrm{Ca}^{2+}$ influx}

We next examined the origin of burst firing in SP cells. Perfusion of zero- $\mathrm{Ca}^{2+}$ bath solution inhibited burst firing, significantly reducing the initial instantaneous AP firing frequency from $154.5 \pm 13.9$ to $61.1 \pm 7.5 \mathrm{~Hz}(n=11, p<0.001$; burst index, $5.86 \pm 0.75$ before, $1.85 \pm 0.28$ after $)$. In contrast, excluding $\mathrm{Ca}^{2+}$ had no significant effect on the initial firing frequency of SL cells $(50.7 \pm 5.1 \mathrm{~Hz}$ before, $48.5 \pm 4.3 \mathrm{~Hz}$ after, $n=5$, $p=0.89$; burst index, $1.34 \pm 0.19$ before, $1.20 \pm 0.15$ after). Thus, burst firing in SP cells requires $\mathrm{Ca}^{2+}$ influx.

What is the subtype of $\mathrm{Ca}^{2+}$ channel involved? Likely candidates are the $\mathrm{Ni}^{2+}$-sensitive $\mathrm{Ca}_{\mathrm{V}} 3$ (T-type) or $\mathrm{Ca}_{\mathrm{V}} 2.3$ (R-type) channels, which have been implicated in burst firing in neocortical and hippocampal pyramidal cells (Magee and Carruth, 1999; Williams and Stuart, 1999; Metz et al., 2005). Perfusion of bath solution containing $100 \mu \mathrm{M} \mathrm{Ni}{ }^{2+}$ abolished burst firing in SP
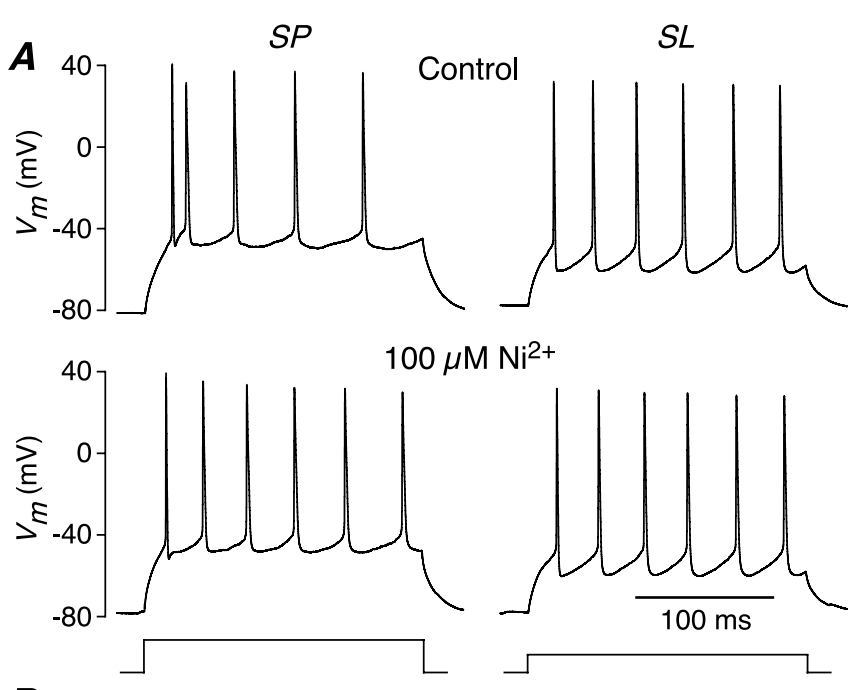

$\boldsymbol{B}$
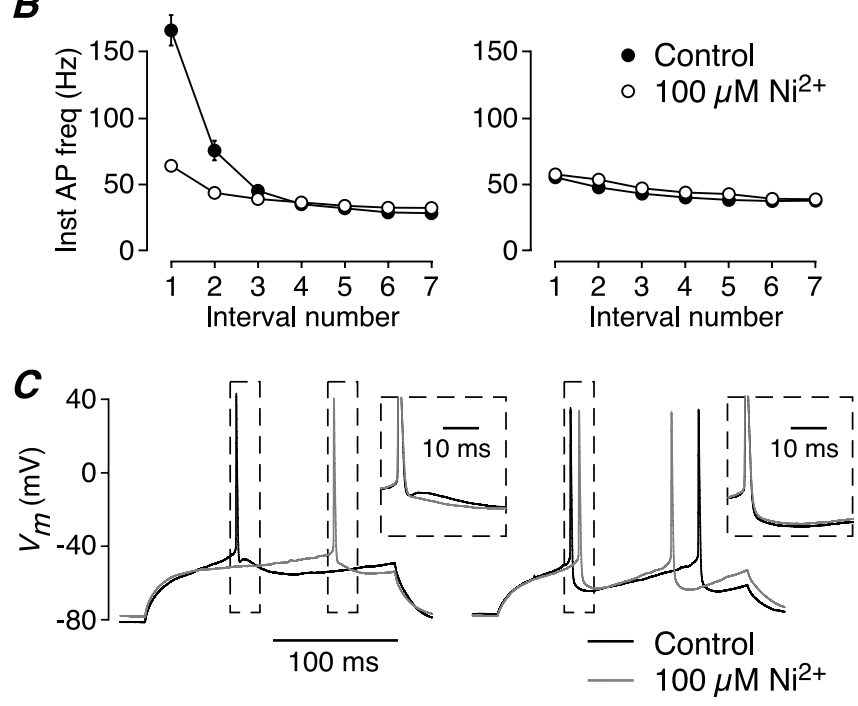

Figure 2. AP bursting in $\mathrm{SP}$ cells requires a $\mathrm{Ni}^{2+}$-sensitive conductance that generates an ADP. A, Bath perfusion of $100 \mu \mathrm{m} \mathrm{Ni}{ }^{2+}$ abolishes burst firing in an SP cell (left; $480 \mathrm{pA}$ current step) but has no effect on the regular firing of an SL cell (right; $240 \mathrm{pA}$ step). $\boldsymbol{B}$, Summary of the effect of $100 \mu \mathrm{M} \mathrm{Ni}{ }^{2+}$ on the averaged instantaneous AP frequency in SP (left; $n=5$ ) and SL cells (right; $n=4)$ ). C, APs recorded just above rheobase in an SP cell (left) and an SL cell (right) before (black trace) and after (gray trace) bath perfusion of $100 \mu \mathrm{M} \mathrm{Ni}^{2+}$ (same cells as in A). In each panel, APs in the dashed boxes (main panel) are shown expanded and aligned in the inset. $\mathrm{Ni}^{2+}$ blocks an ADP in the SP cell but has no effect on the afterhyperpolarization in the SL cell.

cells (Fig. 2A, B, left): the initial firing frequency was reduced from $166.6 \pm 11.5 \mathrm{~Hz}$ in control to $64.1 \pm 1.8 \mathrm{~Hz}$ in $\mathrm{Ni}^{2+}(n=5$, $p=0.001$; burst index, $6.38 \pm 0.80$ before, $2.08 \pm 0.11$ after). In contrast, SL cells were not affected by $\mathrm{Ni}^{2+}$ (Fig. $2 A, B$, right): the initial firing frequency was $55.3 \pm 2.6 \mathrm{~Hz}$ before and $57.5 \pm 3.5$ $\mathrm{Hz}$ after $(n=4, p=0.57$; burst index, $1.51 \pm 0.14$ before, $1.49 \pm$ 0.07 after).

The effect of $\mathrm{Ni}^{2+}$ on excitability is made clear during a current step that is strong enough to fire an AP, but not so strong that burst firing is initiated (Fig. 2C). In SP cells under control conditions, the AP is followed by an afterdepolarization (ADP) (Fig. $2 C$, left, black traces; the contents of the dashed boxes in the main panel are shown aligned and expanded in the inset). This ADP enhances the excitability of the cell for a short time after the first $\mathrm{AP}$, triggering burst firing during stronger depolarizations. $\mathrm{Ni}^{2+}$ $(100 \mu \mathrm{M})$ blocked this ADP, as well as burst firing (Fig. $2 C$, left, gray traces) (ADP, measured $10 \mathrm{~ms}$ after $\mathrm{AP}$, was reduced $8.3 \pm$ 

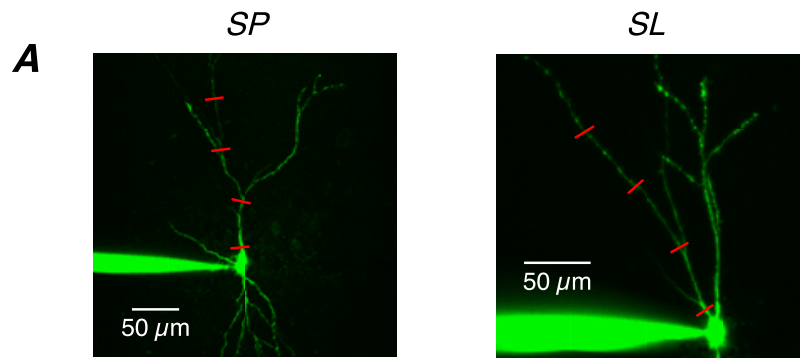

B

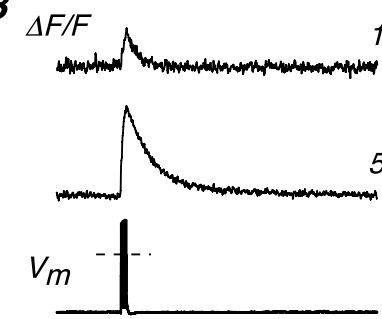

$150 \mu m$
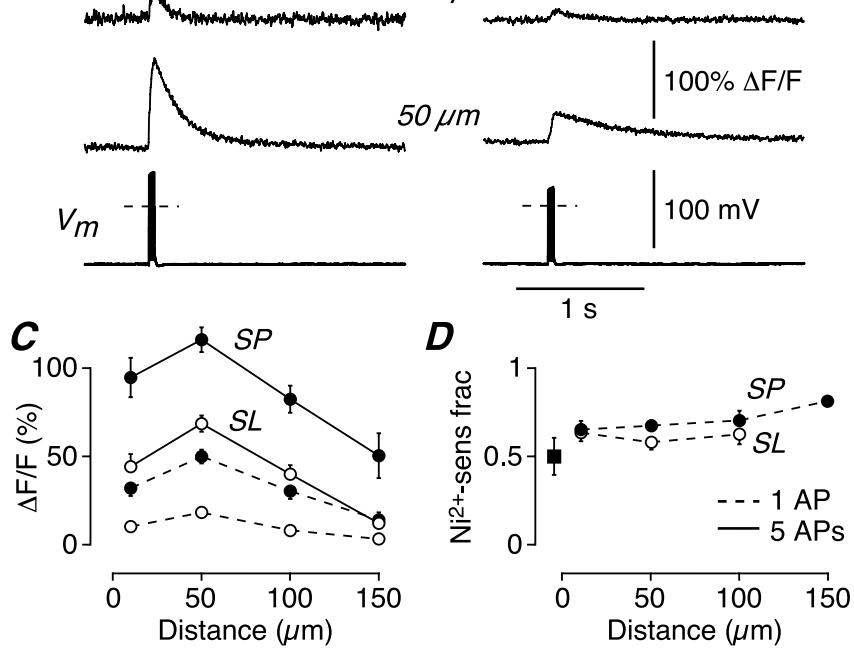

Figure 3. AP-evoked $\mathrm{Ni}^{2+}$-sensitive calcium influx is greater in $\mathrm{SP}$ cells than in $\mathrm{SL}$ cells, suggesting a mechanism for the greater burst firing in SP cells. $A, z$-stack of an SP cell (left) and an SL cell (right) filled with $200 \mu \mathrm{m}$ OGB-1. Line scans were done at the indicated locations on the apical dendrite (red lines). $\boldsymbol{B}$, Normalized changes in OGB-1 fluorescence $(\Delta F / F)$ in response to a $100 \mathrm{~Hz}$ train of five APs elicited by current steps at the soma $\left(V_{\mathrm{m}}\right)$, recorded at 50 and 150 $\mu \mathrm{m}$ from the soma in an SP (left) and SL cell (right). Each line scan is an average of three to four sweeps. The dashed line in the $V_{\mathrm{m}}$ trace indicates $0 \mathrm{mV}$. C, Mean $\Delta F / F$ for SP cells $(n=7-20$; filled circles) and SL cells ( $n=12-33$; open circles), plotted against distance along the apical dendrite from the soma. The continuous lines connect points measured using trains of five APs as in $\boldsymbol{B}$; the dashed lines connect points measured with single AP stimuli. $\boldsymbol{D}$, Mean fraction of $\Delta F / F$ that is sensitive to bath perfusion of $100 \mu \mathrm{M} \mathrm{Ni}^{2+}$, plotted against apical distance from the soma (SP, $n=3-8 ; S L, n=5-14)$. The data shown are for single-AP stimuli; similar results were obtained with trains of five APs. The filled square shows the $\mathrm{Ni}^{2+}$-sensitive fraction measured in a basal dendrite of SP cells, $50 \mu \mathrm{m}$ from the soma. Error bars indicate SEM.

$1.3 \mathrm{mV} ; n=4 ; p=0.008)$. In contrast, SL cells do not exhibit an ADP and $100 \mu \mathrm{M} \mathrm{Ni}^{2+}$ had no effect (Fig. $2 C$, right) ( $V_{\mathrm{m}}$, measured $10 \mathrm{~ms}$ after $\mathrm{AP}$, was increased $0.3 \pm 0.6 \mathrm{mV} ; n=4 ; p=$ $0.63)$.

\section{$\mathrm{Ni}^{2+}$-sensitive $\mathrm{Ca}^{2+}$ influx is larger in SP cells}

If bursting requires $\mathrm{Ni}^{2+}$-sensitive channels and only SP cells burst fire, it should be possible to directly measure a larger $\mathrm{Ni}^{2+}$ sensitive $\mathrm{Ca}^{2+}$ current in SP cells than in SL cells. Unfortunately, it was not possible to test this prediction by measuring currents under whole-cell voltage clamp, because of space-clamp errors. Therefore, we turned to $\mathrm{Ca}^{2+}$ imaging as another method for measuring $\mathrm{Ca}^{2+}$ influx.

After loading with $\mathrm{Ca}^{2+}$ indicator $(200 \mu \mathrm{M}$ Oregon Green BAPTA-1), confocal line scans were made in the apical dendrites at 10, 50, 100, and $150 \mu \mathrm{m}$ from the soma (Fig. $3 A$, red lines). The stimulus was either a single AP, elicited by a strong current step at the soma, or a train of five APs evoked at $100 \mathrm{~Hz}$ ( $V_{\mathrm{m}}$ traces) (Fig. $3 B)$. At all dendritic locations, the total $\mathrm{Ca}^{2+}$ influx in response to the stimulus (measured as $\Delta F / F$ ) was about twice as large in SP
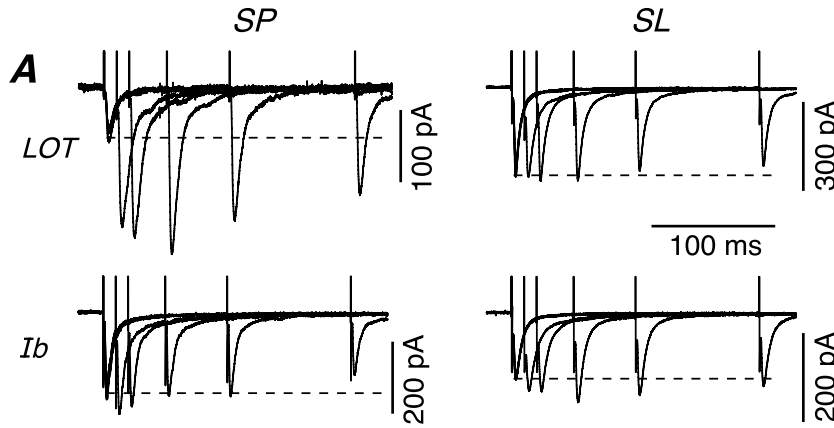

\section{$\frac{\overleftarrow{I}}{8}$}
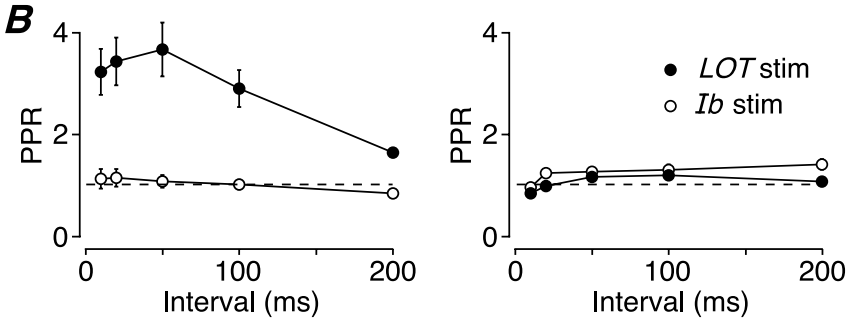

Figure 4. Excitatory synaptic inputs from the LOT onto SP cells are unique in showing strong paired-pulse facilitation. $\boldsymbol{A}$, Typical EPSCs recorded from a voltage-clamped SP (left) or SL cell (right) after paired-pulse extracellular stimulation of either the LOT (top) or layer lb (bottom). Each panel shows five superimposed sweeps (each an average of 5 ) with a range of interpulse intervals. $\boldsymbol{B}$, Mean PPR plotted against interstimulus interval for SP cells (left, $n=12$ for LOT input, $n=6$ for lb input) and SL cells (right, $n=14$ for LOT input, $n=5$ for lb input), after either LOT (filled circles) or lb stimulation (open circles). Error bars indicate SEM.

cells as in SL cells (typical examples in Fig. $3 B$ ) (summary data in Fig. $3 C)(p<0.05)$. This difference was not attributable to saturation of the indicator in SL cells, because the same result was obtained with lower-affinity indicators (see Materials and Methods), and with weak (one AP) and strong (five AP) stimuli (Fig. $3 C$, dashed and solid lines, respectively).

We also measured the $\mathrm{Ni}^{2+}$-sensitive component of $\Delta F / F$ by performing line scans in the same cell before and after bath perfusion of $100 \mu \mathrm{M} \mathrm{Ni}^{2+}$. The $\mathrm{Ni}^{2+}$-sensitive fraction of total $\mathrm{Ca}^{2+}$ influx was not significantly different between SP and SL cells at any distance (average, $0.67 \pm 0.03$ for one AP data shown in Fig. $3 D$; similar result for five AP data). A similar fraction was also measured in the basal dendrites of SP cells at $50 \mu \mathrm{m}$ from the soma (Fig. 3D, filled square).

Together, these results show that, during AP firing, SL cells admit about one-half as much total $\mathrm{Ca}^{2+}$ and, thus, one-half as much $\mathrm{Ca}^{2+}$ through $\mathrm{Ni}^{2+}$-sensitive channels on their dendrites as do SP cells. Presumably, this difference, along with other factors (see Discussion), is sufficient to account for the finding that SP cells exhibit $\mathrm{Ni}^{2+}$-sensitive burst firing and SL cells do not.

\section{LOT inputs onto SP cells uniquely exhibit strong} paired-pulse facilitation

We next turned to the synaptic properties of SP and SL cells, taking advantage of the laminar structure of the piriform cortex to selectively stimulate the two main excitatory inputs to these neurons, the LOT (afferent) and layer Ib (associational/commissural) inputs. Paired stimuli were delivered at different interstimulus intervals to either the LOT (Fig. $4 A$, top panels) or layer Ib (Fig. $4 A$, bottom panels), and the resultant EPSCs were recorded in either SP cells (Fig. 4A, left panels) or SL cells (Fig. 4A, right panels). Surprisingly, stimulation of the same afferent (LOT) input produced strong paired-pulse facilitation in SP cells but not in SL cells (Fig. 4A, top panels). Stimulation of the associational (layer $\mathrm{Ib}$ ) input produced little short-term plasticity in 
either cell type (Fig. 4A, bottom panels). The data were summarized by plotting the mean paired-pulse ratio (PPR) (amplitude of the second EPSC divided by the amplitude of the first) for each stimulus interval (Fig. $4 B$ ) (SP data at left, $n=12$; SL data at right, $n=14$ ). Maximal facilitation for the LOT-SP cell synapse was $3.66 \pm 0.53$ at a $50 \mathrm{~ms}$ interval, significantly greater than that for the LOT-SL cell synapse $(1.18 \pm 0.08 ; p<0.001)$. In additional experiments, we recorded simultaneously from an SP and an SL cell and found that a single stimulating electrode in the LOT again produced facilitation only in the SP cell $(3.56 \pm 0.51$; cf. $1.19 \pm$ 0.09 in the SL cell; $n=8$ ).

In an additional series of experiments, we compared the shortterm plasticity of AMPA receptor-mediated EPSCs and NMDA receptor-mediated EPSCs, to check whether this facilitation was attributable to increased transmitter release (Zucker and Regehr, 2002). Because AMPA and NMDA receptors are colocalized postsynaptically at synapses (Bekkers and Stevens, 1989), changes in presynaptic glutamate release should be reported equally by both kinds of receptor. This was indeed the case: NMDA and AMPA EPSCs exhibited identical strong paired-pulse facilitation at the LOT-SP cell synapse (PPR, $3.66 \pm 0.53, n=12$, for AMPA; $3.62 \pm 0.33, n=22$, for NMDA; 50 ms interval, $p=0.95)$ and weak facilitation at the LOT-SL cell synapse (PPR, $1.18 \pm 0.08$ for AMPA, $1.29 \pm 0.08$ for NMDA; $n=14$ for both; $p=0.34$ ). Hence, the different facilitation seen at the two synapses has a presynaptic origin.

\section{Two mechanisms of paired-pulse facilitation at LOT-SP cell synapses}

We next asked whether the strong facilitation at LOT-SP synapses was attributable to residual $\mathrm{Ca}^{2+}$ inside the presynaptic terminal during the interval between the paired stimuli. If so, facilitation will be blocked by intraterminal application of the slow $\mathrm{Ca}^{2+}$ chelator, EGTA (Zucker and Regehr, 2002). Indeed, superfusion of EGTA-AM (30 $\mu \mathrm{M}$ for $>15 \mathrm{~min}$, allowing accumulation of EGTA in the cytoplasm) greatly reduced facilitation in SP cells (PPR, $2.79 \pm 0.37$ before, $1.23 \pm 0.05$ after; $50 \mathrm{~ms}$ interval; $n=4 ; p=0.02$ ) (Fig. $5 A$, left), although having little effect on the amplitude of the first EPSC (ratio after/before, $0.92 \pm 0.11 ; p=0.34)$. In SL cells, treatment with EGTA-AM converted weak facilitation into paired-pulse depression (PPR, $1.13 \pm 0.17$ before, $0.67 \pm 0.06$ after; $50 \mathrm{~ms}$ interval; $n=4 ; p=$ 0.03 ) (Fig. $5 A$, right), again with little effect on the first EPSC (amplitude ratio after/before, $0.86 \pm 0.17 ; p=0.41$ ). Thus, residual $\mathrm{Ca}^{2+}$ is very important for facilitation in LOT-SP terminals, but it also has an effect in LOT-SL terminals, in which it overcomes an underlying paired-pulse depression.

This underlying depression at LOT-SL synapses suggests that these terminals may have a higher probability of neurotransmitter release $\left(P_{\mathrm{r}}\right)$, allowing stimulus-dependent depletion of synaptic vesicles (Zucker and Regehr, 2002). Conversely, lower $P_{\mathrm{r}}$ at LOT terminals onto SP cells will assist the facilitation seen at this synapse. Thus, in a second series of experiments, we used the MK-801 technique (Rosenmund et al., 1993) to compare $P_{\mathrm{r}}$ at LOT synapses onto SP and SL cells. Progressive block by $2 \mu \mathrm{M}$ (+)-MK-801 of the NMDA EPSC was significantly slower for the LOT-SP cell input (Fig. 5B) (SP cells: mean 50\% block after $12.6 \pm 1.7$ stimuli, $n=13$; SL cells: mean $50 \%$ block after $6.3 \pm$ 0.6 stimuli, $n=10 ; p=0.004)$. These results confirm that LOT afferents form lower- $P_{\mathrm{r}}$ synapses onto SP cells than onto SL cells. We conclude that LOT-SP synapses strongly facilitate for two reasons: the effect of residual $\mathrm{Ca}^{2+}$, and lower $P_{\mathrm{r}}$.
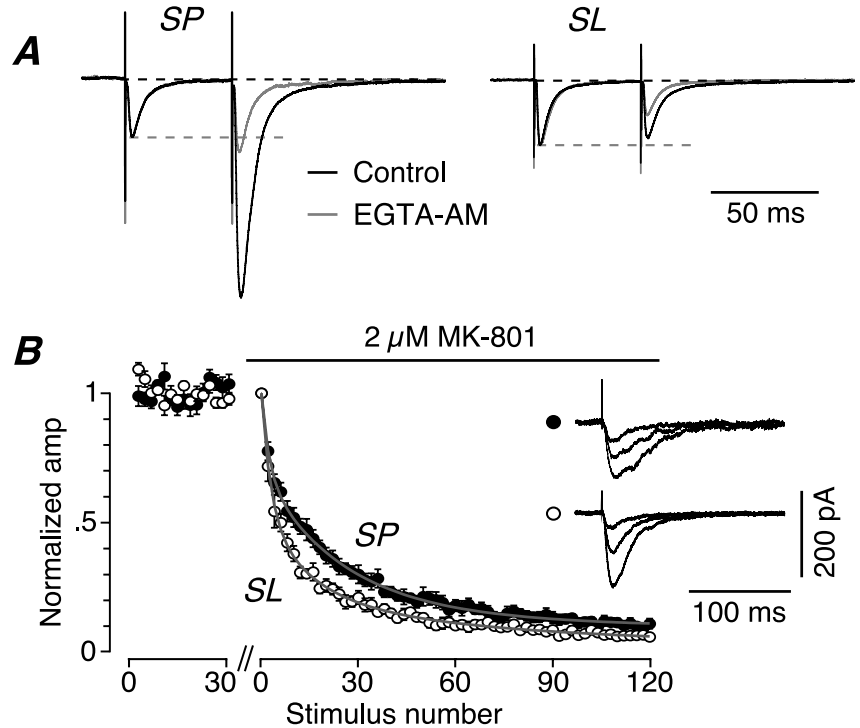

Figure 5. Paired-pulse facilitation of LOT inputs onto SP cells is explained by the effect of residual calcium and a smaller probability of neurotransmitter release. $A$, EPSPs recorded in an SP cell (left) and an SL cell (right) before (black traces) and after (gray traces) superfusion of bath solution containing $30 \mu \mathrm{m}$ EGTA-AM, after paired-pulse stimulation of LOT inputs ( 50 ms interstimulus interval). Traces are averages of 20 sweeps and have been normalized to the amplitude of the first EPSP. EGTA-AM blocks paired-pulse facilitation at LOT-SP synapses and unmasks an underlying paired-pulse depression at LOT-SL synapses. $\boldsymbol{B}$, Averaged normalized time course plots for the progressive block of NMDA EPSCs by $2 \mu \mathrm{M}$ MK- 801 during $0.1 \mathrm{~Hz}$ stimulation of LOT inputs onto SP cells ( $n=13$; filled circles) or SL cells ( $n=10$; open circles). Stimulation was paused for 10 min during the break on the abscissa to allow addition of MK-801. NMDA EPSC amplitudes from two consecutive stimuli were averaged together. The rate of block is slower for SP cells, suggesting a smaller release probability at the LOT-SP cell synapse. The insets show NMDA EPSCs, simultaneously recorded from an SP cell (top) and an SL cell (bottom), averaged from stimuli numbers 2-3, 8-9, and 60-61 after perfusion of MK-801.

\section{SL cells exhibit a large afterhyperpolarization that suppresses excitability}

We next explored differences between SP and SL cells during synaptic stimulation in current-clamp experiments (cf. voltageclamp experiments, above). Weak LOT stimulation elicited an EPSP in an SP cell (Fig. 6, left) or an SL cell (Fig. 6, right) that was either just below threshold (Fig. 6, gray traces) or just above threshold (Fig. 6, black traces) for firing an AP. The subtheshold EPSP was much more prolonged in SL cells (Fig. $6 \mathrm{~A}$, right, gray trace), consistent with the larger membrane time constant of these smaller neurons. However, if the EPSP fired an action potential in an SL cell, the AP generated a strong afterhyperpolarization (AHP) that dramatically attenuated the falling phase of the EPSP (Fig. 6A, right, black trace) (amplitude change, $-12.4 \pm 1.1 \mathrm{mV} ; n=5)$. This effect was much less pronounced in SP cells (Fig. 6A, left) (amplitude change, $-3.8 \pm 0.2 \mathrm{mV} ; n=4$; $p=0.001$ cf. SL cells).

Repeating this experiment with an artificial EPSP, produced by injecting a current at the soma (see Materials and Methods), had a similar effect: the AHP amplitude change after a single AP in SL cells was $-12.8 \pm 0.8 \mathrm{mV}$, significantly greater than in SP cells $(-6.5 \pm 1.0 \mathrm{mV} ; n=6$ for SL, $n=4$ for SP; $p=0.003$ ) (data not illustrated). This confirms that the larger AHP in SL cells is an intrinsic property of the APs in these cells and is not attributable to synaptic conductances.

What is the consequence of this behavior for the excitability of SP and SL cells? This was tested by applying a train of five weak LOT stimuli at $40 \mathrm{~Hz}$, which is similar to the physiological pattern of inputs received from the olfactory bulb (Cang and Isaacson, 
A
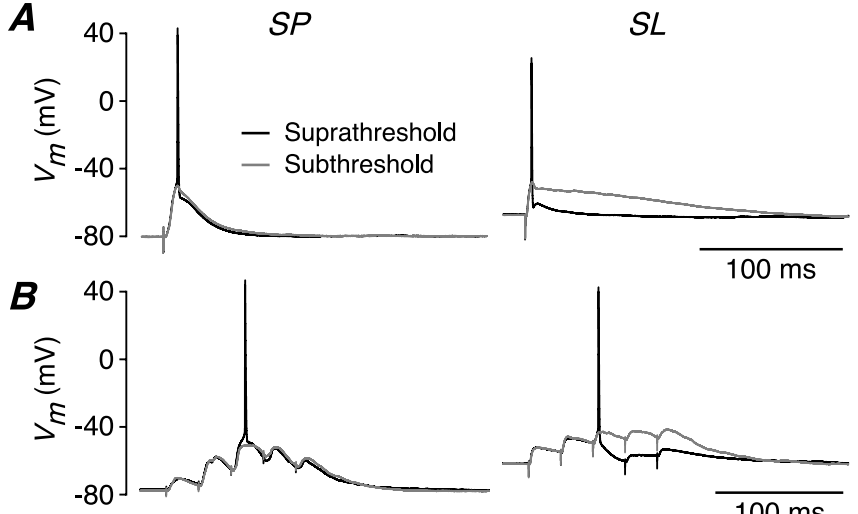

$100 \mathrm{~ms}$

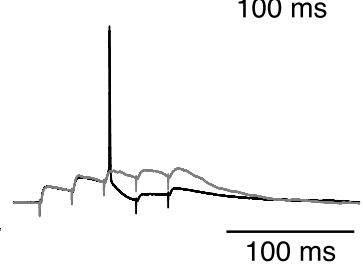

Figure 6. Synaptically evoked APs are followed by a prominent AHP in SL cells but not in SP cells. $A$, Weak LOT stimulation elicits an EPSP that is either just subthreshold (gray traces) or just suprathreshold (black traces) for firing an AP in either an SP cell (left) or an SL cell (right). The subthreshold EPSP in the SL cell (gray trace, right) is prolonged because of the longer membrane time constant of these smaller neurons. However, if the EPSP fires an AP, the resultant AHP dramatically attenuates the falling phase of the EPSP (black trace, right). This effect is much less prominent in SP cells (left panel). $\boldsymbol{B}$, The same experiment repeated with a train of five LOT stimuli at $40 \mathrm{~Hz}$. In an SP cell (left), the firing of an AP has little effect on later EPSPs, but in an SL cell (right) the AHP after an action potential suppresses later EPSPs. A similar effect is seen for layer Ib stimulation (data not illustrated).

2003) (see below). In SL cells (Fig. 6B, right), the AHP after an action potential markedly suppressed later EPSPs (by $-13.2 \pm$ $0.9 \mathrm{mV} ; n=5$ ), whereas in SP cells (Fig. $6 B$, left) the later EPSPs were much less affected by an earlier AP $(-3.3 \pm 0.8 \mathrm{mV} ; n=5$; significantly different from SL cells, $p<0.001)$. A similar difference was seen for layer Ib (Assn) stimulation (SL cells: $-14.4 \pm$ $1.3 \mathrm{mV}, n=6$; SP cells: $-3.5 \pm 1.0 \mathrm{mV}, n=5 ; p<0.001$ ) (data not illustrated). Thus, APs suppress subsequent neuronal excitability in SL cells because of their larger AHPs, but this effect is much smaller in SP cells.

\section{Frequency coding by SP and SL cells in response to naturalistic stimulation}

So far, we have shown that the two main classes of principal neurons in the main input layer of the piriform cortex, SP and SL cells, are functionally distinctive. SP cells tend to fire bursts of APs followed by ADPs or smaller AHPs and receive strongly facilitating afferent input. SL cells tend to fire regular-spiking APs with larger AHPs and their afferent input does not facilitate. Thus, for several reasons, SP cells are more excitable than SL cells. What are the ramifications of these differences for the in vivo operation of these two cell types?

The major input to the piriform cortex is provided by the LOT, which comprises the output of mitral/tufted (M/T) cells in the olfactory bulb. In vivo experiments have shown that, in response to odorant stimulation, many M/T cells fire short bursts of 2-10 APs at $\sim 40 \mathrm{~Hz}$, the bursts repeating at the respiration frequency $(\sim 2 \mathrm{~Hz})$ (Cang and Isaacson, 2003; Margrie and Schaefer, 2003). It has been reported that rodents are able to accurately discriminate odors within a single sniff cycle (Uchida and Mainen, 2003; Abraham et al., 2004), suggesting that olfactory decoding requires only a single burst of APs. We approximated naturalistic stimulation of SP and SL cells in slices of piriform cortex by applying a single train of five stimuli at $40 \mathrm{~Hz}$. Because there is uncertainty about the strength of inputs to individual SP and SL cells in vivo (Neville and Haberly, 2004), we also explored the effects of a range of stimulus strengths.

Figure $7 A$ summarizes experiments in which $40 \mathrm{~Hz}$ trains of five stimuli were applied to the LOT and the responses recorded under current clamp in SP cells (red) or SL cells (black). The mean frequency of AP firing was plotted against the stimulator setting, normalized to the setting that first generated on average one AP (Fig. 7A; dashed lines connect the data points for individual cells; circles represent the mean for each cell type near that stimulus strength; $n=10$ for SP, $n=6$ for SL). SP cells and SL cells responded very differently to this patterned stimulation. At twice stimulus threshold, SP cells typically started firing on the second EPSP because of paired-pulse facilitation (Fig. 4), and then fired a single AP on each of the subsequent EPSPs (Fig. $7 B$, trace 1). Hence, the output firing frequency of SP cells was the same as the input frequency $(40 \mathrm{~Hz})$. SL cells also typically started firing on the second EPSP because of temporal summation of slowly decaying EPSPs (Fig. 6), but then fired a single AP on every second EPSP (Fig. 7B, trace 2), because of the inhibitory effect of the prominent AHP (Fig. 6). Hence, the output firing frequency of SL cells was only $20 \mathrm{~Hz}$, one-half the input frequency.

Differences were also prominent at four times the stimulus threshold. In SP cells, the larger EPSPs now often generated an initial burst of APs (Fig. $7 B$, trace 3), reflecting the propensity of these cells to burst fire (Fig. 1). Hence, the output firing frequency was greater than the input frequency. In contrast, in SL cells, the larger EPSPs now overcame the inhibitory effect of the AHP, but only a single action potential was triggered by each EPSP (Fig. 7B, trace 4) because these cells do not burst fire (Fig. 1). Hence, the output firing frequency was the same as the input, $40 \mathrm{~Hz}$. In summary, then, naturalistic stimulation of LOT inputs caused SP cells to fire at about twice the frequency of SL cells for all stimulus strengths.

The output of SP and SL cells is thought to provide the input to other SP and SL cells in a combinatorial manner, via associational/commissural fibers in layer Ib (Neville and Haberly, 2004) (Fig. 7E). Thus, in a second series of experiments, we replayed the outputs from LOT stimulation as inputs to layer Ib. These layer Ib inputs were of three broad types: (1) $40 \mathrm{~Hz}$ trains (like Fig. $7 B$, output traces 1 and 4); (2) $20 \mathrm{~Hz}$ trains (like Fig. 7B, output trace 2); and (3) a $40 \mathrm{~Hz}$ train with an initial burst of two APs (like Fig. $7 B$, output trace 3 ). Figure $7 C$ summarizes the output of SP (red) and SL (black) cells in response to input pattern (1). The results were similar to LOT stimulation (Fig. 7A), except that SP cells tended to burst more strongly with layer Ib stimulation at higher stimulus strengths (Fig. 7C;D, example traces). Qualitatively similar results were obtained with input patterns (2) (Fig. $8 A, B$ ) and (3) (Fig. 8C,D).

What are the implications of these results for frequency coding? We showed that a naturalistic $40 \mathrm{~Hz}$ train at the LOT is transformed by two layers of interconnected SP and SL cells into different patterns of output firing, summarized in Figures $7 C$ and 8, $A$ and $C$. Assuming that SP and SL cells (1) receive similar LOT input from the olfactory bulb, and (2) randomly form similar numbers of associational/commissural connections with each other (Fig. 7E) (Haberly and Price, 1978), then the net output of the piriform cortex can be estimated by combining the three plots in Figures $7 C$ and $8, A$ and $C$. The result is shown in Figure $7 F$ (for details, see Materials and Methods). The top and bottom shaded bands represent the range of mean AP firing frequencies (mean \pm 1SD) produced by SP and SL cells, respectively, after two layers of synaptic processing. Thus, according to this model, the piriform cortex transforms inputs received from the olfactory bulb by producing an output of dispersed AP frequencies, in which the range of dispersal depends on the strength of synaptic input. 


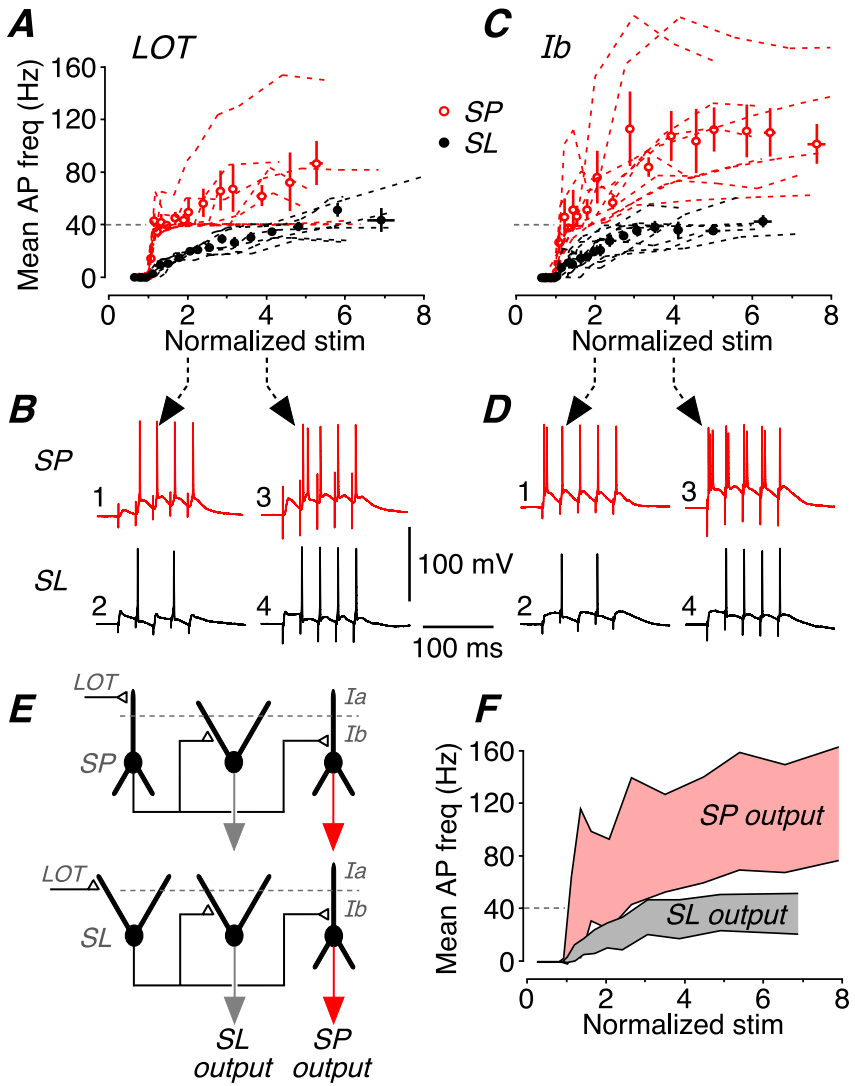

Figure 7. SP and SL cells perform different frequency transformations on a naturalistic stimulus. $\boldsymbol{A}, \mathrm{A}$ train of five stimuli at $40 \mathrm{~Hz}$ was applied to the LOT, mimicking typical in vivo output of the olfactory bulb during a sniff. The mean firing frequency of the resultant postsynaptic APs was measured over a range of stimulus strengths. This panel shows the mean firing frequency for SP cells (red; $n=9$ ) and SL cells (black; $n=6$ ) plotted against stimulus strength, normalized to the strength that first generates one AP on average. The dashed lines are the data for individual cells; the circles show the mean of all cells of that type ( \pm SEM). $\boldsymbol{B}$, Illustrative postsynaptic responses measured in an SP cell (top; red) and an SL cell (bottom; black) at either twice (left) or four times (right) the stimulus threshold for firing an AP. With the weaker stimulus, the SP cell reliably follows the $40 \mathrm{~Hz}$ input train, whereas the $\mathrm{SL}$ cell fires at $20 \mathrm{~Hz}$ because of the large afterhyperpolarization after each AP. With the stronger stimulus, the SP cell fires an initial burst of APs, whereas the SL cell now fires a single AP on each EPSP. C, Summary data for the same experiment done with layer $\mathrm{lb}$ (Assn) stimulation at $40 \mathrm{~Hz}$ ( $n=10$ for SP and SL). This resembles the response to LOT stimulation $(A)$, except that SP cells tend to burst more strongly after lb stimulation. $\boldsymbol{D}$, Illustrative postsynaptic responses to layer lb stimulation, displayed as in $\boldsymbol{B}$. $\boldsymbol{E}$, Simplified canonical circuit of the piriform cortex. Two circuits are shown, differing by the identity of the neuron that first receives LOT input (to layer la) from the olfactory bulb (SP cell, top; SL cell, bottom). The response to LOT stimulation then passes to SP and SL cells in the second layer of synaptic processing, the Assn inputs in layer lb. $\boldsymbol{F}$, Averaged output of the model in $\boldsymbol{E}$ after two layers of synaptic processing (LOT, and then Assn). The shaded pink band represents the mean AP firing frequency ( \pm 1SD) at the output of SP cells; the shaded gray band represents the output of $S L$ cells. The two cell types generate broad, yet distinctive, ranges of AP firing frequencies that depend on the strength of synaptic input.

\section{Temporal coding by SP and SL cells in response to} naturalistic stimulation

We also examined the propagation of spike timing through the canonical circuit (Fig. 7E) during naturalistic stimulation. For each EPSP in the train that fired an AP, and for every stimulus strength, the latency from the stimulus time to the peak of the AP was 2-4 ms longer for SP cells than for SL cells (Fig. 9A, B, top) ( $p<0.015$; LOT data illustrated; layer Ib data similar). However, the jitter in AP timing was small $(<120 \mu \mathrm{s})$ and not significantly different between the two cell types (Fig. $9 B$, bottom) ( $n=6$ for both types; $p>0.15$ ).

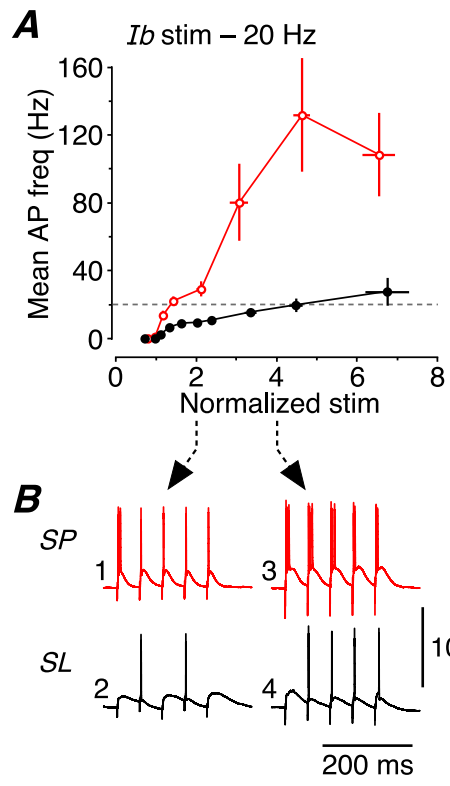

C Ib stim - bursting $40 \mathrm{~Hz}$

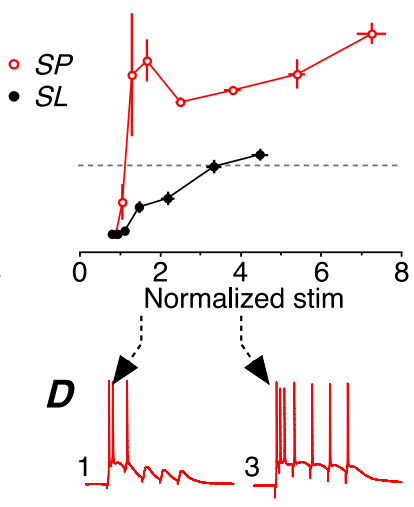

Figure 8. Responses of SP and SL cells to two other patterns of naturalistic layer lb (Assn) stimulation $(20 \mathrm{~Hz}$, and bursting $40 \mathrm{~Hz})$. These stimulus patterns were taken from the responses of both cell types to regular $40 \mathrm{~Hz}$ stimulation of the LOT (Fig. 7). A, Mean AP firing frequencies of SP cells (red; $n=4$ ) and SL cells (black; $n=5$ ) in response to a $20 \mathrm{~Hz}$ train of stimuli applied to layer $\mathrm{lb}$, representing the typical output of SL cells with weaker $40 \mathrm{~Hz} \mathrm{~L} 0 \mathrm{~T}$ stimulation (Fig. $7 B$, trace 2). The data were normalized as in Figure 7. Error bars indicate SEM. $\boldsymbol{B}$, Illustrative postsynaptic responses to $20 \mathrm{~Hz}$ layer Ib stimulation, measured in an SP cell (top; red) and an SL cell (bottom; black) at either twice (left) or four times (right) the stimulus threshold for firing an action potential. $C$, Averaged data for the same experiment done with a bursting $40 \mathrm{~Hz}$ stimulus applied to layer Ib (SP, $n=5 ; \mathrm{SL}, n=4)$. This stimulus, representing the averaged $(n=10)$ output of SP cells with stronger $40 \mathrm{~Hz}$ LOT stimulation (Fig. 7B, trace 3), comprised two initial stimuli at an interval of $6 \mathrm{~ms}(166 \mathrm{~Hz})$ followed by four stimuli at $40 \mathrm{~Hz}$. D, Illustrative postsynaptic responses to this bursting $40 \mathrm{~Hz}$ layer $\mathrm{lb}$ stimulation, displayed as in $\boldsymbol{B}$ except that here traces 1 and 2 show the result of stimulation at 1.5 times the AP threshold (not twice threshold, as in $\boldsymbol{B})$.

\section{Discussion}

Here, we show that the two major types of principal neurons in the densely packed input layer of the piriform cortex, layer II, have strikingly different synaptic and firing properties. SP cells receive strongly facilitating excitatory synaptic inputs from the olfactory bulb and fire bursts of action potentials. SL cells receive nonfacilitating inputs from the bulb and fire nonbursting action potentials that are followed by a powerful afterhyperpolarization. These distinctive properties determine the response of each cell type to the physiological stimulus received by the piriform cortex from the olfactory bulb (i.e., a brief $\sim 40 \mathrm{~Hz}$ burst of APs generated by a single sniff). SP cells tend to respond by producing output APs at $\geq 40 \mathrm{~Hz}$, whereas SL cells tend to produce output APs at $\leq 40 \mathrm{~Hz}$, depending on the strength of olfactory input. Thus, the piriform cortex transforms inputs by dispersing the firing frequency. Our results highlight the importance of cellular properties, including those of the long-neglected semilunar cells, to coding strategies in the piriform cortex.

\section{Different firing properties}

The most likely explanation of the burst firing in SP cells is the presence of $\mathrm{Ni}^{2+}$-sensitive $\mathrm{Ca}_{\mathrm{V}} 2.3$ (R-type) or $\mathrm{Ca}_{\mathrm{V}} 3.1-3$ (T-type) voltage-gated $\mathrm{Ca}^{2+}$ channels, which have been implicated in burst firing in other types of pyramidal cells (Williams and Stuart, 1999; Metz et al., 2005). This is consistent both with the known role of an ADP in some forms of burst firing (Swensen and Bean, 
$\boldsymbol{A}$
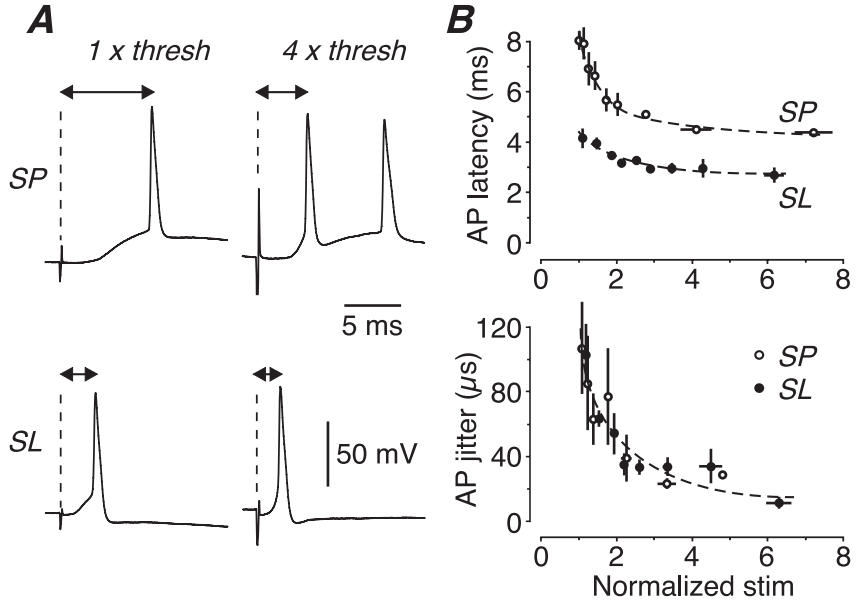

Figure 9. Latency and jitter responses of SP and SL cells to a naturalistic stimulus. $A$, Examples of the first AP generated by a five pulse, $40 \mathrm{~Hz}$ train of LOT stimuli, recorded in an SP cell (top) and an SL cell (bottom) at threshold (left) or four times threshold (right) for firing one AP. The synaptic latency becomes smaller in both cells at the higher stimulus strength but is always briefer in the SL cell. $\boldsymbol{B}$, Mean latency from the stimulus artifact to the peak of the AP (top), and mean jitter in AP timing (bottom), both plotted against normalized stimulus strength, using LOT stimulation (SP, open circles, $n=6$; SL, filled circles, $n=6$ ). Latency is consistently briefer in SL cells, but jitter is not significantly different between the two cell types. Error bars indicate SEM. Similar results were obtained for layer lb (Assn) stimulation (data not illustrated).

2003; Metz et al., 2005) and our finding that only SP cells possess an ADP, which is blocked by $\mathrm{Ni}^{2+}$ (Fig. 2). Surprisingly, however, SL cells also showed a significant $\mathrm{Ni}^{2+}$-sensitive influx of $\mathrm{Ca}^{2+}$ ( $\sim 50 \%$ of that in SP cells) in measurements using fluorescence imaging (Fig. 3). If SL cells possess the requisite ion channels, why do they not show at least some burst firing? The answer may be that a threshold level of $\mathrm{Ca}^{2+}$ influx is required for burst firing. As well as having a twofold larger $\mathrm{Ca}^{2+}$ influx in each dendrite, SP cells possess more dendrites (both apical and basal) emanating from the soma, which is close to the presumed spike initiation zone in the axon. Together, these may deliver a much larger $\mathrm{Ca}^{2+}$-dependent depolarization to the axon in SP cells than in SL cells.

The imaging also revealed that total $\mathrm{Ca}^{2+}$ influx declines steeply with distance along the dendrite when APs are evoked by a current step at the soma (Fig. 3C). This may reflect either a decline in $\mathrm{Ca}^{2+}$ channel density or an attenuation of the backpropagating AP with distance (Häusser et al., 2000). Electrical recordings from the dendrites have not been reported for neurons in the piriform cortex.

The larger AHP in SL cells (Fig. 6) is probably attributable to several factors, including (1) the more depolarized resting potential of SL cells ( $-68.8 \mathrm{vs}-74.7 \mathrm{mV}$ for SP cells), giving a larger driving force for the $\mathrm{K}^{+}$-mediated AHP; (2) the larger input resistance of SL cells, meaning that a given AHP conductance will produce a larger hyperpolarization; and (3) the presence of an ADP in SP cells, which counteracts the AHP.

\section{Different synaptic properties}

Previous work using both extracellular (Haberly, 1973) and intracellular recordings (Bower and Haberly, 1986; Hasselmo and Bower, 1990) has shown paired-pulse facilitation of EPSPs after stimulation of LOT, but not layer Ib, inputs to layer II neurons. This agrees with our findings for SP cells, but not for SL cells (Fig. $4 A$ ), suggesting that SL cells were formerly overlooked.

Our experiments suggest two reasons for the distinctive paired-pulse facilitation of LOT inputs onto SP cells. First, we show that EGTA-AM blocks this facilitation (Fig. 5A), suggesting that it is attributable to residual $\mathrm{Ca}^{2+}$ in the presynaptic terminal (Katz and Miledi, 1968; Zucker and Regehr, 2002). EGTA-AM has less effect on LOT-SL synapses, but does unmask a pairedpulse depression (Fig. 5A). This suggests that residual $\mathrm{Ca}^{2+} \mathrm{ac}^{2}$ cumulates less in these SL boutons, possibly because they contain a higher concentration of endogenous $\mathrm{Ca}^{2+}$ buffer than boutons contacting SP cells (Burnashev and Rozov, 2005). Second, we show using MK-801 that LOT-SP synapses have a lower release probability $\left(P_{\mathrm{r}}\right)$ than LOT-SL synapses (Fig. $5 B$ ). Lower $P_{\mathrm{r}}$ is commonly associated with greater paired-pulse facilitation (Zucker and Regehr, 2002), as we observe in SP cells. Although residual $\mathrm{Ca}^{2+}$ is probably the dominant factor here, the lower $P_{\mathrm{r}}$ at LOT-SP synapses is consistent with the lack of synaptic depression in SP cells after EGTA-AM, contrasting with the depression seen in SL cells (Fig. 5A).

Our experiments thus show that different boutons of the same afferent pathway, the LOT, have different properties depending on the postsynaptic target. A similar phenomenon has been reported for excitatory synapses onto pyramidal cells and different classes of interneurons in the hippocampus and neocortex (Thomson, 1997; Markram et al., 1998; Reyes et al., 1998; Koester and Johnston, 2005). Is it possible that SL cells, with their regularspiking APs and distinctive LOT input, are a kind of GABAergic interneuron? This seems unlikely, because they express the glutamate-synthesizing enzyme PAG (phosphate-activated glutaminase) (Kaneko and Mizuno, 1988) but not the GABAsynthesizing enzyme GAD (glutamate decarboxylase) (Ekstrand et al., 2001), and their axonal projections are wide-ranging, typical of excitatory principal neurons (Neville and Haberly, 2004; Yang et al., 2004).

\section{Importance for olfactory coding}

We explored the progression of AP firing patterns through the piriform cortex using a simple two-layered iterative approach. First, we applied to the LOT a "naturalistic" train of stimuli modeled on the pattern recorded in vivo (Cang and Isaacson, 2003) and recorded the AP responses in SP and SL cells. Second, we applied the three broad types of AP responses (40,20, and $40 \mathrm{~Hz}$ with an initial burst) to layer Ib (Assn) inputs and again recorded the responses in SP and SL cells. In this way, we explored each of the four possible combinations of connections between layer II principal cells: SP-SP, SL-SL, SP-SL, and SL-SP (Fig. 7E). The overall effect was to disperse output AP firing patterns across a broad range. This output then passes to other brain regions (Haberly and Price, 1978). What is the significance of this result for olfactory coding?

Odors are encoded in the olfactory bulb as a chemotopic map of activated glomeruli (Mori et al., 1999) that may evolve over time (Mazor and Laurent, 2005). How this map is conveyed to the piriform cortex is unclear, but a number of findings offer clues about how it might occur. Psychophysical (Wilson, 2001) and anatomical (Illig and Haberly, 2003; Zou et al., 2005) studies suggest that the piriform cortex performs some kind of integrative computation, assembling the unitary odorant information from the bulb into a singular odor percept. Recent electrophysiological data also support the idea that olfactory coding is broad and distributed in the cortex (Franks and Isaacson, 2006). As in other brain regions, however, the precise nature of this coding remains uncertain (deCharms and Zador, 2000; Lledo et al., 2005). Traditionally, coding is presented as a dichotomy between rate coding and temporal coding (Harris, 2005). Rate 
coding in the olfactory system is supported by work on insect olfaction (Laurent, 2002), but this needs to be reconciled with evidence that rodents can reliably identify odorants within 100 ms (Uchida and Mainen, 2003; Abraham et al., 2004), which places an upper limit on the integration time for odor recognition (Friedrich, 2006). Temporal coding is supported by the prominence of oscillations in the working olfactory system (Neville and Haberly, 2004), but is hindered by uncertainty about the origins, and even the relevance, of these oscillations (Fontanini and Bower, 2005; Murakami et al., 2005; Sejnowski and Paulsen, 2006).

Our results complement and extend these ideas. We show that heterogeneity of neurons in the main input layer of the piriform cortex, layer II, leads to a dispersal in the pattern of AP firing as it progresses through two layers of the canonical circuit. This is compatible with the emergence of a broad, distributed code in the piriform cortex (Franks and Isaacson, 2006). We measured changes in the mean AP firing rate over a single sniff cycle (Fig. 7) (related to rate coding), as well as changes in AP latency and jitter (Fig. 9) (related to temporal coding). AP firing rate and latency, but not jitter, were both dispersed to an extent that depended on the strength of synaptic input (Figs. 7F, 9B). Thus, assuming that input strength-dependent dispersal is a relevant parameter for olfactory coding (Franks and Isaacson, 2006), our results allow us to exclude spike-timing precision as a basis for coding (Billimoria et al., 2006), but not AP firing rate or latency.

In summary, we have described an unexpected cellular heterogeneity in the piriform cortex, with implications for olfactory coding. Although this coding is likely to be complex, information about the underlying physiology will help to refine our understanding of the likely strategies used by this brain region for recognizing and remembering odors.

\section{References}

Abraham NM, Spors H, Carleton A, Margrie TW, Kuner T, Schaefer AT (2004) Maintaining accuracy at the expense of speed: stimulus similarity defines odor discrimination time in mice. Neuron 44:865-876.

Barkai E, Hasselmo ME (1994) Modulation of the input/output function of rat piriform cortex pyramidal cells. J Neurophysiol 72:644-658.

Bekkers JM, Delaney AJ (2001) Modulation of excitability by $\alpha$-dendrotoxin-sensitive potassium channels in neocortical pyramidal neurons. J Neurosci 21:6553-6560.

Bekkers JM, Stevens CF (1989) NMDA and non-NMDA receptors are colocalized at individual excitatory synapses in cultured rat hippocampus. Nature 341:230-233.

Billimoria CP, DiCaprio RA, Birmingham JT, Abbott LF, Marder E (2006) Neuromodulation of spike-timing precision in sensory neurons. J Neurosci 26:5910-5919.

Bower JM, Haberly LB (1986) Facilitating and nonfacilitating synapses on pyramidal cells: a correlation between physiology and morphology. Proc Natl Acad Sci USA 83:1115-1119.

Burnashev N, Rozov A (2005) Presynaptic $\mathrm{Ca}^{2+}$ dynamics, $\mathrm{Ca}^{2+}$ buffers and synaptic efficacy. Cell Calcium 37:489-495.

Cang J, Isaacson JS (2003) In vivo whole-cell recording of odor-evoked synaptic transmission in the rat olfactory bulb. J Neurosci 23:4108-4116.

deCharms RC, Zador A (2000) Neural representation and the cortical code. Annu Rev Neurosci 23:613-647.

Ekstrand JJ, Domroese ME, Feig SL, Illig KR, Haberly LB (2001) Immunocytochemical analysis of basket cells in rat piriform cortex. J Comp Neurol 434:308-328.

Fontanini A, Bower JM (2005) Variable coupling between olfactory system activity and respiration in ketamine/xylazine anesthetized rats. J Neurophysiol 93:3573-3581.

Franks KM, Isaacson JS (2005) Synapse-specific downregulation of NMDA receptors by early experience: a critical period for plasticity of sensory input to olfactory cortex. Neuron 47:101-114.

Franks KM, Isaacson JS (2006) Strong single-fiber sensory inputs to olfactory cortex: implications for olfactory coding. Neuron 49:357-363.

Friedrich RW (2006) Mechanisms of odor discrimination: neurophysiological and behavioral approaches. Trends Neurosci 29:40-47.

Gellman RL, Aghajanian GK (1993) Pyramidal cells in piriform cortex receive a convergence of inputs from monoamine activated GABAergic interneurons. Brain Res 600:63-73.

Haberly LB (1973) Summed potentials evoked in opossum prepyriform cortex. J Neurophysiol 36:775-788.

Haberly LB (1983) Structure of the piriform cortex of the opossum. I. Description of neuron types with Golgi methods. J Comp Neurol 213:163-187.

Haberly LB, Bower JM (1984) Analysis of association fiber system in piriform cortex with intracellular recording and staining techniques. J Neurophysiol 51:90-112.

Haberly LB, Price JL (1978) Association and commissural fiber systems of the olfactory cortex of the rat. I. Systems originating in the piriform cortex and adjacent areas. J Comp Neurol 178:711-740.

Harris KD (2005) Neural signatures of cell assembly organization. Nat Rev Neurosci 6:399-407.

Hasselmo ME, Bower JM (1990) Afferent and association fiber differences in short-term potentiation in piriform (olfactory) cortex of the rat. J Neurophysiol 64:179-190.

Hasselmo ME, Bower JM (1992) Cholinergic suppression specific to intrinsic not afferent fiber synapses in rat piriform (olfactory) cortex. J Neurophysiol 67:1222-1229.

Häusser M, Spruston N, Stuart GJ (2000) Diversity and dynamics of dendritic signaling. Science 290:739-744.

Illig KR, Haberly LB (2003) Odor-evoked activity is spatially distributed in piriform cortex. J Comp Neurol 457:361-373.

Johnson DMG, Illig KR, Behan M, Haberly LB (2000) New features of connectivity in piriform cortex visualized by intracellular injection of pyramidal cells suggest that "primary" olfactory cortex functions like "association" cortex in other sensory systems. J Neurosci 20:6974-6982.

Kaneko T, Mizuno N (1988) Immunohistochemical study of glutaminasecontaining neurons in the cerebral cortex and thalamus of the rat. J Comp Neurol 267:590-602.

Kapur A, Pearce RA, Lytton WW, Haberly LB (1997) GABA $_{\mathrm{A}}$-mediated IPSCs in piriform cortex have fast and slow components with different properties and locations on pyramidal cells. J Neurophysiol 78:2531-2545.

Katz B, Miledi R (1968) The role of calcium in neuromuscular facilitation. J Physiol (Lond) 195:481-492.

Koester HJ, Johnston D (2005) Target cell-dependent normalization of transmitter release at neocortical synapses. Science 308:863-866.

Laurent G (2002) Olfactory network dynamics and the coding of multidimensional signals. Nat Rev Neurosci 3:884-895.

Lledo PM, Gheusi G, Vincent JD (2005) Information processing in the mammalian olfactory system. Physiol Rev 85:281-317.

Magee JC, Carruth M (1999) Dendritic voltage-gated ion channels regulate the action potential firing mode of hippocampal CA1 pyramidal neurons. J Neurophysiol 82:1895-1901.

Margrie TW, Schaefer AT (2003) Theta oscillation coupled spike latencies yield computational vigour in a mammalian sensory system. J Physiol (Lond) 546:363-374.

Markram H, Wang Y, Tsodyks M (1998) Differential signaling via the same axon of neocortical pyramidal neurons. Proc Natl Acad Sci USA 95:5323-5328.

Mazor O, Laurent G (2005) Transient dynamics versus fixed points in odor representations by locust antennal lobe projection neurons. Neuron 48:661-673.

Metz AE, Jarsky T, Martina M, Spruston N (2005) R-type calcium channels contribute to afterdepolarization and bursting in hippocampal CA1 pyramidal neurons. J Neurosci 25:5763-5773.

Mori K, Nagao H, Yoshihara Y (1999) The olfactory bulb: coding and processing of odor molecule information. Science 286:711-715.

Murakami M, Kashiwadani H, Kirino Y, Mori K (2005) State-dependent sensory gating in olfactory cortex. Neuron 46:285-296.

Neville KR, Haberly LB (2004) Olfactory cortex. In: The synaptic organization of the brain, Ed 5 (Shepherd GM, ed), pp 415-454. New York: Oxford UP. 
Protopapas AD, Bower JM (2001) Spike coding in pyramidal cells of the piriform cortex of rat. J Neurophysiol 86:1504-1510.

Reyes A, Lujan R, Rozov A, Burnashev N, Somogyi P, Sakmann B (1998) Target-cell-specific facilitation and depression in neocortical circuits. Nat Neurosci 1:279-285.

Rosenmund C, Clements JD, Westbrook GL (1993) Nonuniform probability of glutamate release at a hippocampal synapse. Science 262:754-757.

Sejnowski TJ, Paulsen O (2006) Network oscillations: emerging computational principles. J Neurosci 26:1673-1676.

Swensen AM, Bean BP (2003) Ionic mechanisms of burst firing in dissociated Purkinje neurons. J Neurosci 23:9650-9663.

Thomson AM (1997) Activity-dependent properties of synaptic transmission at two classes of connections made by rat neocortical pyramidal axons in vitro. J Physiol (Lond) 502:131-147.

Uchida N, Mainen ZF (2003) Speed and accuracy of olfactory discrimination in the rat. Nat Neurosci 6:1224-1229.

ul Quraish A, Yang J, Murakami K, Oda S, Takayanagi M, Kimura A, Kakuta S, Kishi K (2004) Quantitative analysis of axon collaterals of single su- perficial pyramidal cells in layer IIb of the piriform cortex of the guinea pig. Brain Res 1026:84-94.

Williams SR, Stuart GJ (1999) Mechanisms and consequences of action potential burst firing in rat neocortical pyramidal neurons. J Physiol (Lond) 521:467-482.

Wilson DA (2001) Receptive fields in the rat piriform cortex. Chem Senses 26:577-584.

Wilson DA (2003) Rapid, experience-induced enhancement in odorant discrimination by anterior piriform cortex neurons. J Neurophysiol 90:65-72.

Yang J, ul Quraish A, Murakami K, Ishikawa Y, Takayanagi M, Kakuta S, Kishi K (2004) Quantitative analysis of axon collaterals of single neurons in layer IIa of the piriform cortex of the guinea pig. J Comp Neurol 473:30-42.

Zou Z, Li F, Buck LB (2005) Odor maps in the olfactory cortex. Proc Natl Acad Sci USA 102:7724-7729.

Zucker RS, Regehr WG (2002) Short-term synaptic plasticity. Annu Rev Physiol 64:355-405. 